\title{
MULTILETRAMENTOS EM PERSPECTIVA: O INFOGRÁFICO WEB COMO RECURSO DIDÁTICO
}

\author{
Bruna Carolini Barbosa ${ }^{1}$ (PPGEL/UEL-CAPES) \\ Prof ${ }^{a}$. Ana Lúcia de Campos Almeida (Orientadora)
}

\section{RESUMO}

$\mathrm{Na}$ sociedade mediada pelas novas tecnologias a relação entre imagem e palavra é facilmente percebida, a sociedade está cada vez mais visual. Disso decorre a importância em se refletir sobre os letramentos multimodais, já que a apreensão do sentido em sua totalidade só se dá através da leitura que integra as diferentes linguagens de um texto. Pautados em aportes teóricos como Bronckart (2006); Shepherd e Watters (1999); Marcuschi (2005), Pinheiro (2010), Dionísio (2011), Kato (1995), Solé (1998), Paiva (1998), entre outros e considerando a escola uma importante agência de letramento, este artigo propõe-se a discutir a relevância em se abordar o infográfico web como um recurso didático em sala de aula, uma vez que esse dispositivo pode beneficiar o processo de ensino-aprendizagem, uma vez que permite facilitar a compreensão de ideias e conteúdos complexos e extensos, incentiva o pensamento crítico e o desenvolvimento de ideias, além de conjugar vários tipos de informação. Pretende-se com este trabalho contribuir com a prática docente interessada em romper com os padrões autônomos de letramento em favor de uma perspectiva multissemiótica e que considere o aluno como sujeito histórico-socialmente situado.

Palavras-chave: multiletramentos, infográfico web, multimodalidade.

\section{AS AULAS DE LÍNGUA PORTUGUESA E AS ATIVIDADES DE LEITURA}

O ensino de Língua Portuguesa, há muito, segue o modelo tradicional de ensino, que privilegia os textos verbais em detrimento dos não verbais. Muitos professores estão em sala de aula reproduzindo o modelo autônomo de letramento, ensinando língua exclusivamente como estrutura e sem considerar que os alunos estão envolvidos em variados contextos comunicativos e que os usos que farão da língua dependerão desses contextos.

A primazia pelas normas e estruturas gramaticais e seu ensino superestimado em sala de aula estão intimamente relacionados ao que Street (2014) chama de "modelo autônomo de letramento" que considera a escrita como uma modalidade linguística superior, capaz de desenvolver no indivíduo o raciocínio lógico, inteligência, pensamento superior e analítico, como defendiam os teóricos da grande divisa entre oralidade e escrita (GOODY, 1969; ONG,1982; OLSON, 1977).

A manutenção e efetivação do letramento autônomo se consegue através de diversos meios, como o distanciamento entre língua e sujeitos e ensino voltado exclusivamente ao aprendizado dos microaspectos da língua, dessa forma as práticas em sala de aula têm perpetuado as formas tradicionais de ensino e mesmo as que se dizem mais modernas

1

E-mail: profabruna_lp@yahoo.com.br 


\section{SEMINÁRIO DE PESQUISA EM CIÊNCIAS HUMANAS - SEPECH \\ Humanidades, Estado e desafios didático-científicos \\ Londrina, 27 a 29 de julho de 2016}

continuam reproduzindo em sala de aula a concepção de língua como um código a ser desvendado e adquirido na escola e que não leva em consideração os sujeitos da aprendizagem e seu contexto socio-cultural. Entretanto, uma nova concepção de linguagem tem, aos poucos, direcionado as práticas em sala de aula: a interação toma o lugar da exposição de conteúdos; a língua deixa de ser vista meramente como expressão do pensamento ou como instrumento de comunicação.

Com o avanço das pesquisas na área do ensino-aprendizagem de línguas e sua apropriação e reprodução pelos documentos norteadores, uma nova visão sobre a linguagem fez com que surgisse a necessidade em se repensar a prática docente e os modelos de ensino. A comunicação humana é mediada pela linguagem e efetivada por meio dos gêneros, estes, por sua vez, são ferramentas de expressão escrita e oral na esfera social; são igualmente ferramentas de ensino, "megainstrumentos" didáticos (DOLZ; NOVERRAZ; SCHNEUWLY, 2004). Os gêneros são objetos de ensino, são "quadros de atividade social em que as ações de linguagem se realizam" (BRONCKART, 1999).

$\mathrm{O}$ ensino da língua por meio dos gêneros permite aos alunos o acesso às significações que tem lugar nas interações humanas que existem fora da escola, permitindo a ampliação das capacidades de linguagem, "é através dos gêneros que as práticas de linguagem materializam-se nas atividades dos aprendizes" (SCHNEUWLY e DOLZ, 2004, p.15).

\section{GÊNEROS MULTIMODAIS E MULTILETRAMENTOS}

O surgimento da internet influenciou as interações humanas, agiu sobre a forma pela qual nos comunicamos e isso fez com que novos gêneros emergissem, esses gêneros são os então chamados "gêneros digitais" (MARCUSCHI, 2005; PINHEIRO, 2015; SHEPERD \& WATTERS, 1999). Shepherf e Watters (1999) consideram que a combinação entre computador e internet fizeram que os gêneros passassem por diversas alterações, fazendo com que novos gêneros emergissem e alguns já existentes fossem reconfigurados; em relação aos novos gêneros os autores enfatizam como sua grande marca a funcionalidade, passando a chamá-los de cybergêneros.

Braga (2013), discorre sobre a migração das linguagens usadas em meios analógicos para o meio digital levando ao que ela chama de "hibridização" de linguagens. Isso faz com que novas formas comunicativas passem a circular no meio social e por decorrência, os novos letramentos. A autora debate em seu texto sobre a pressão sofrida pelas pessoas em dominar as novas práticas comunicativas.

A internet possibilitou a quebra de barreiras de tempo e espaço e seu uso não é mais entendido como opção, mas como demanda social, citando como exemplo operações que só podem ser realizadas pela internet, o que obriga as pessoas a fazerem uso dessa tecnologia, assim como declaração de imposto de rende e editais de concurso. Braga (2013) emprega o termo "analfabyte" para aqueles que não dominam essas novas formas de linguagem e são forçados a aprender.

Marcuschi (2001) fala sobre a necessidade de indagar-se sobre a presença dos gêneros digitais no domínio das atividades escolares no que se refere às práticas da escrita, bem como rever a questão mais ampla do papel da escola no letramento e a função do computador no ensino. O computador é comum nas escolas, entretanto reflexões críticas 


\section{SEMINÁRIO DE PESQUISA EM CIÊNCIAS HUMANAS - SEPECH \\ Humanidades, Estado e desafios didático-científicos \\ Londrina, 27 a 29 de julho de 2016}

sobre seu uso em sala de aula são escassas. $\mathrm{O}$ autor considera que o computador entrou na escola, mas ainda não foram pensados seus usos educacionais, o que o leva a concluir que "o que entrou na escola foi uma ideologia e não um instrumento", chamando a atenção para a rapidez com que o instrumento tem tomado o espaço educacional.

Os meios digitais reconfiguraram as formas de ler. Enunciados multissemióticos e hipertextuais levam a novas formas de leitura, mas que essas práticas não são tão inovadoras quanto parecem e, para comprovar sua tese, contrasta o cenário atual com algumas mudanças que aconteceram ao longo da história e que mostram que as mudanças surgem conforme as necessidades comunicativas e de construção de sentidos das pessoas se acentuam, por exemplo, a criação da imprensa, o telefone e o fax (BRAGA, 2013)

A tecnologia está dando continuidade a esse processo e possibilita a integração de diversos modos de comunicação, um exemplo claro é a materialização de um fenômeno humano que é a tendência de construir conhecimento em redes intertextuais: o hipertexto é a concretização dessa rede de relações. A despeito disso, Dionísio e Vasconcelos (2013, p.19), enfatizam que "a sociedade na qual estamos inseridos se constitui como um grande ambiente multimodal, no qual palavras, imagens, sons, cores, músicas, aromas, movimentos variados, texturas, formas diversas se combinam e estrutura, um grande mosaico multissemiótico".

Essas ferramentas tecnológicas têm permitido a democratização dos conhecimentos e a participação ativa dos sujeitos na produção e reprodução de conhecimento. Permite que as pessoas tracem seus próprios caminhos da leitura e assumam o papel de autor/leitor, além do surgimento das comunidades virtuais, principalmente por meio das redes sociais.

Inevitavelmente essas transformações chegam ao âmbito escolar e levam a novas formas de letrar. Isso não deve ser visto como algo assustador, mas como vantagem e principalmente como uma possibilidades de dinamizar o ensino, tornar as aprendizagens mais significativas e interessantes e aproximar a escola da sociedade e seus avanços, não restringindo as aulas ao uso exclusivo do livro didático.

Dionísio (2011) ao refletir sobre os gêneros multimodais e sua emergência nas diversas mídias, ilustra suas reflexões com uma pesquisa sobre a leitura de infográficos, e depois chama a atenção para a necessidade que há em incluir esses novos gêneros em sala de aula, entretanto faz isso de forma bastante crítica, chamando a atenção para o domínio dos alunos e professores ao lidarem com esses gêneros com maior complexidade de linguagens. É inegável que os textos multimodais merecem espaço em sala de aula, todavia, é fundamental refletir, a priori, se o professor e o aluno estão de fato preparados para lidar com essas significativas mudanças na forma de apreensão dos gêneros. Vale notar a contribuição de Rojo e Moura (2012, p.8), no que diz respeito ao ensino dos textos multimodais:

Trabalhar com multiletramentos pode ou não envolver (normalmente envolverá) o uso de novas tecnologias da comunicação e de informação ('novos letramentos'), mas caracteriza-se como um trabalho que parte das culturas de referência do alunado (popular, local, de massa) e de gêneros, mídias e linguagens por eles conhecidos, para buscar um enfoque crítico, pluralista, ético e democrático - que envolva agência - de textos/discursos que ampliem o repertório cultural, na direção de outros letramentos [...]. Oliveira (2013) discute a origem do termo letramento até sua revisão por Dionísio 


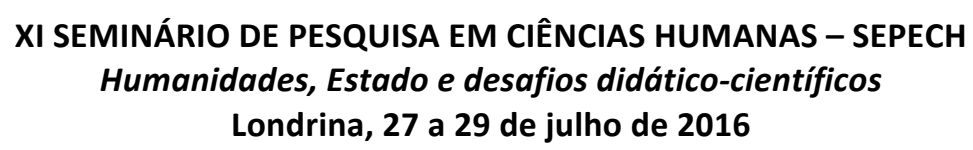

(2006), que segundo a autora, "propõe uma revisão do conceito de letramento sugerindo o termo multiletramentos para designar a capacidade de atribuir e produzir sentidos a mensagens multimodais" (OLIVEIRA, 2013 apud DIONÍSIO, 2011). Tomando como base esse conceito somos levados a pensar sobre a importância em se desenvolver no contexto escolar práticas que englobem as múltiplas linguagens constitutivas desses textos.

\section{A LEITURA DO GÊNERO INFOGRÁFICO WEB}

Um novo leitor surge em meio aos textos multimodais que integram várias linguagens: o leitor navegador. Com o advento das novas tecnologias o leitor é levado à novas informações e configurações; antes disso as informações eram levadas prontas para o ambiente escolar e a pesquisa restringia-se à enciclopédias.

A leitura pode ser compreendida como um processo dinâmico e não linear e por isso complexo. No universo digital é considerada um processo importante que integra várias linguagens.De acordo com Kato (1995, p. 107),

A leitura pode ser entendida como um conjunto de habilidades que envolve estratégias de vários tipos. Essas habilidades seriam: a de encontrar parcelas significativas do texto; a de estabelecer relações de sentido e de referência entre certas parcelas do texto; a de estabelecer coerência entre as proposições do texto; a de avaliar a verossimilhança e a consistência das informações extraídas; a de inferir o significado e o efeito pretendido pelo autor do texto.

Vale notar a contribuição de Solé (1998, p. 73), no que diz repeito às estratégias para o ensino da leitura:

Compreender os propósitos implícitos e explícitos da leitura; ativar e aportar à leitura conhecimentos prévios relevantes para o conteúdo em questão; dirigir a atenção ao fundamental; avaliar a consistência interna do conteúdo expressado e sua compatibilidade com o conhecimento prévio e com o "sentido comum"; Comprovar continuamente se a compreensão ocorre mediante a revisão e a recapitulação periódica e a auto-interrogação; elaborar e provar inferências de diverso tipo, como interpretação, hipóteses e previsões e conclusões.

A complexidade da leitura se dá pelos vários domínios de processamento nos níveis lexical, sintático, semântico local, semântico global e processamento integrativo, em que se realizam operações complexas dadas sua dinamicidade, auto-organização - o que faz com que cada leitor processe a leitura de forma particular - e interação entre seus componentes, que requer, além de habilidades como leitores, habilidade em lidar com os fatores que podem interferir na leitura em todos os domínios do processamento.

Paiva (2009), sugere um roteiro para o processamento da leitura:

1. o processamento lexical: reconhecimento do leitor das palavras do texto, bem como seus morfemas.

2. o processamento sintático: reconhecimento do leitor das ligações sintáticas possíveis entre as palavras de uma sentença.

3. a construção da coerência (ou significado) local: reconhecimento do leitor das proposições possíveis para uma sentença formada por palavras.

4. a construção da coerência temática: reconhecimento do leitor das relações entre sentenças; formação de inferências. 


\section{SEMINÁRIO DE PESQUISA EM CIÊNCIAS HUMANAS - SEPECH \\ Humanidades, Estado e desafios didático-científicos \\ Londrina, 27 a 29 de julho de 2016}

5. construção da coerência externa ou processamento integrativo: reconhecimento do leitor da produção de informações feita por ele durante a leitura, comparando-a com as informações que já dispõe para efetuar juízos de valor acerca do que leu: foi-lhe útil, mudou sua forma de pensar sobre o assunto, alterou sua memória a respeito daquele assunto? (PAIVA, 2009 apud COSCARELLI, 1999, p. 51).

Embora cada leitor processe a leitura de forma particular, os textos possuem elementos que nos encaminham para direções semelhantes. No caso dos infográficos, além dos elementos linguísticos, a ocorrência de outras linguagens como o design, imagens, sons, etc., nos conduzem à construção de sentidos, o que não significa que os sentidos construídos serão iguais, mas que "giram em torno de uma gama de possibilidades" (COSCARELLI; NOVAIS, 2015). Por conta dessas novas linguagens constituintes dos textos multimodais, é preciso que a Linguística supere a noção de texto como "unidade verbal" e passe a concebê-lo como uma unidade que comporta elementos de outras modalidades que, juntamente com o verbal, constituirão os significados.

A leitura pode ser entendida como "uma atividade na qual se leva em conta as experiências e os conhecimentos do leitor [...] uma vez que o texto não é simples produto da codificação de um emissor a ser decodificado por um receptor passivo" (KOCH, 2011, p.11).

Os documentos oficiais corroboram com a concepção de leitura em sentido mais amplo, conceituando a leitura como, para os Parâmetros Curriculares Nacionais (1998, p. 69) podemos entendê-la como, processo no qual o leitor realiza um trabalho ativo de compreensão e interpretação do texto, a partir de seus objetivos, de seu conhecimento sobre o assunto, sobre o autor, de tudo o que sabe sobre a linguagem etc. Não se trata de extrair informação, decodificando letra por letra, palavra por palavra. Trata-se de uma atividade que implica estratégias de seleção, antecipação, inferência e verificação, sem as quais não é possível proficiência. É o uso desses procedimentos que possibilita controlar o que vai sendo lido, permitindo tomar decisões diante de dificuldades de compreensão, avançar na busca de esclarecimentos, validar no texto suposições feitas.

O gênero infográfico é um texto em que diversas linguagens são empregadas para a construção do sentido global, portanto, são textos multimodais. Os infográficos podem compor partes de notícias e reportagens, mas podem aparecer independentes de outros gêneros; são utilizados para explicar fenômenos, processos, conceitos, que necessitam de dinamicidade dada a complexidade e extensão de seu conteúdo. Denominados Infográfico $W e b$ os que são encontrados nos meios virtuais, altamente interativos e que combinam sons e imagens em movimento.

Nesse sentido, Paiva (2009), adaptou o roteiro para o processamento da leitura adequando-o especificamente para a leitura do gênero infográfico:

1. Processamento de partes das imagens: responsável pelo reconhecimento de partes das imagens: elementos primários como brilhos, cores, linhas limítrofes, etc.

2. Processamento das relações entre partes da imagem: construção das relações entre as partes da imagem, estrutura das imagens, como os elementos primários, processados anteriormente se relacionam aqui.

3. Construção do sentido local: construção do sentido entre as partes de uma imagem, qual o sentido da relação entre as partes: por exemplo: a relação entre brilho e cor forma uma explosão?

4. Construção do sentido global: construção do sentido entre as imagens do infográfico. Como as imagens se relacionam umas com as outras? 


\section{SEMINÁRIO DE PESQUISA EM CIÊNCIAS HUMANAS - SEPECH \\ Humanidades, Estado e desafios didático-científicos \\ Londrina, 27 a 29 de julho de 2016}

Para a leitura do texto eletrônico é preciso que o leitor saiba identificar o que é link, aba, ícone, botão, etc., assim como é preciso que ele saiba processar a gramática/sintaxe que é própria ao texto digital. Embora cada suporte tenha características peculiares, o leitor pode transferir conhecimentos do universo impresso para o digital e vice-versa.

As atividades de leitura, geralmente, debruçam-se sobre a decodificação do código linguístico, sem abordar profundamente o plano do sentido, e pensando nisso é que propomos um trabalho que contrarie essa prática, sugerindo a leitura do gênero infográfico web segundo uma perspectiva de análise que o concebe em três dimensões: contextual, discursiva e verbo-visual (PAIVA, 2011).

A primeira dimensão de análise, a contextual, destina-se às atividades que dizem respeito à descrição dos componentes do texto em questão, seu suporte, objetivo, intencionalidade, ou seja, sua função pragmática. A segunda dimensão, a discursiva, diz respeito ao conteúdo temático do texto e suas estratégias retóricas, buscando identificar como os assuntos foram desenvolvidos no texto para uma composição temática final. Nessa etapa o trabalho se destina à função comunicativa do infográfico.A terceira dimensão do trabalho debruça-se sobre a análise da relação entre a informação verbal e não verbal do texto, ou seja, da materialidade linguística.

Paiva (2011) propõe as dimensões contextual, discursiva e verbo-visual para a análise do gênero infográfico, não especificamente para fins pedagógicos, mas mais como uma forma de elementarização do gênero, partindo daí é possível pensar em sua didatização, torná-lo instrumento de ensino. Para tanto sugerimos a engenharia didática disposta na tabela a seguir que poderá ser aplicada em infográficos diversos e adaptada de acordo com as necessidades que forem surgindo ao longo do trabalho; a tabela é apenas uma forma de nortear o desenvolvimento do projeto didático, mas jamais de engessar a criatividade docente. Vale Ressaltar que o trabalho foi sistematizado por meio de oficinas e as mesmas não possuem um tempo estimado, devido ao fato de que o tempo a ser investido em cada uma das etapas está condicionado, como já mencionado anteriormente, às necessidades da turma. 


\section{SEMINÁRIO DE PESQUISA EM CIÊNCIAS HUMANAS - SEPECH \\ Humanidades, Estado e desafios didático-científicos \\ Londrina, 27 a 29 de julho de 2016}

\section{PROPOSTA DE ENSINO}

\section{Oficina 1 Oficina 2 Oficina Oficina 4 Oficina 5 Oficina 6 Oficina}

Conteúdo Apresentaç LetramentoDiscussão Análise Análise Análise Avaliação ão dano Gênero do tema contextua Discursiv Verbo -com base

Proposta de 1 doa doVisual dona leitura Ensino e do Gênero infográfic infográfic infográfic de um

Infográfico

$$
\text { o } \quad 0 \quad \text { infográfic }
$$

Web

\begin{tabular}{|c|c|c|c|c|c|c|c|}
\hline Objetivo & $\begin{array}{l}\text { Verificar } \\
\quad \text { o } \\
\text { conheci } \\
\text { mento } \\
\text { prévio } \\
\text { dos } \\
\text { alunos } \\
\text { com } \\
\text { relação } \\
\text { ao } \\
\text { gênero }\end{array}$ & $\begin{array}{l}\text { Reconhec } \\
\text { er as } \\
\text { regularida } \\
\text { des do } \\
\text { Gênero }\end{array}$ & $\begin{array}{l}\text { Constata } \\
\mathrm{r} \\
\text { conheci } \\
\text { mento } \\
\text { dos } \\
\text { alunos } \\
\text { quanto } \\
\text { ao tema } \\
\text { e ampliar } \\
\text { seus } \\
\text { conheci } \\
\text { mentos } \\
\text { por meio } \\
\text { de } \\
\text { diversos } \\
\text { gêneros }\end{array}$ & $\begin{array}{l}\text { Realiza } \\
\text { r um } \\
\text { levanta } \\
\text { mento } \\
\text { do } \\
\text { aspecto } \\
\text { context } \\
\text { ual do } \\
\text { gênero } \\
\text { escolhi } \\
\text { do }\end{array}$ & $\begin{array}{l}\text { Identifi } \\
\text { car as } \\
\text { constru } \\
\text { ções } \\
\text { discursi } \\
\text { vas } \\
\text { present } \\
\text { es no } \\
\text { texto }\end{array}$ & $\begin{array}{l}\text { Averig } \\
\text { uar a } \\
\text { correlaç } \\
\text { ão entre } \\
\text { os } \\
\text { compon } \\
\text { entes } \\
\text { verbo- } \\
\text { visuais } \\
\text { empreg } \\
\text { ados no } \\
\text { infográf } \\
\text { ico }\end{array}$ & $\begin{array}{l}\text { Consid } \\
\text { erar os } \\
\text { conheci } \\
\text { mentos } \\
\text { apreend } \\
\text { idos } \\
\text { por } \\
\text { meio de } \\
\text { uma } \\
\text { atividad } \\
\text { e } \\
\text { compos } \\
\text { ta por } \\
\text { questõe } \\
\text { s que } \\
\text { aborde } \\
\text { m as } \\
\text { dimens } \\
\text { ôes } \\
\text { context } \\
\text { ual, } \\
\text { discursi } \\
\text { va e } \\
\text { verbo- } \\
\text { visual } \\
\text { do } \\
\text { gênero } \\
\text { infográf } \\
\text { ico }\end{array}$ \\
\hline
\end{tabular}

Fonte: Elaborada pela autora. 


\section{SEMINÁRIO DE PESQUISA EM CIÊNCIAS HUMANAS - SEPECH \\ Humanidades, Estado e desafios didático-científicos \\ Londrina, 27 a 29 de julho de 2016}

\section{CONSIDERÇÕES FINAIS}

Este trabalho teve como propósito discutir as transformações que o surgimento dos gêneros multimodais acarretam no trabalho docente no que diz respeito ao ensino da leitura. A multissemiose textual faz refletir sobre a necessidade em se superar o modelo autônomo de letramento, em que normas gramaticais e o distanciamento entre a língua e o sujeito são o foco do trabalho.

É urgente a inserção dos textos multimodais em sala de aula, pois a sociedade tem alterado suas formas comunicacionais e a escola deve acompanhar essa demanda, já que é na escola que o sujeito é preparado para agir socialmente e isso só é possível através do domínio dos gêneros que circulam nas diferentes esferas comunicativas. Vale ressaltar que, embora a multimodalidade não seja exclusivamente uma característica dos gêneros digitais, a abordagem dos cybergêneros em sala de aula é também de fundamental importância.

Em vista disso, além das discussões sobre a relevância em se inserir os gêneros digitais em sala de aula, este trabalho preocupou-se em apontar como a sistematização e didatização do gênero infográfico web é algo possível e aplicável em diferentes situações, uma vez que este gênero oferece inúmeras possibilidades temáticas, podendo ser adequado à contextos distintos e que não exige, necessariamente, um grande aparato tecnológico, nem mesmo altas habilidades por parte do professor, uma vez que é preciso pensar que essas dificuldades são comuns. Ressaltamos, por fim, a necessidade em se propor e divulgar opções metodológicas para o trabalho com os gêneros digitais, uma vez que, muitos profissionais reconhecem a importância da inserção dos mesmos, mas carecem de propostas metodológicas para fazê-lo.

\section{REFERÊNCIAS}

BRAGA, D. B. Tecnologia da informação e comunicação e novos letramentos. In. Ambientes digitais: reflexões teóricas e práticas. São Paulo: Cortez, 2013. p. $39-46$.

BRONCKART, J.-P. Atividade de linguagem, textos e discursos: por um interacionismo sócio-discursivo. Trad. Anna Rachel Machado e Péricles Cunha. São Paulo: EDUC, 1999.

. Os tipos de discurso. In.: Atividade de linguagem, discurso e desenvolvimento humano. Campinas: Mercado de Letras, 2006.

COSCARELLI, C. V.; NOVAIS, A. E.. Leitura: um processo cada vez mais complexo. Disponível em: $<$ http://revistaseletronicas.pucrs.br/ojs/index.php/fale/article/viewFile/8118/5807> Data de acesso: 04 de maio de 2015.

DIONISIO, A. P. Gêneros textuais e multimodalidade. In.: KARWOSKI, Acir Mário; GAYDECZKA; B., SLEBENEICHE K. (Orgs.). Gêneros textuais: reflexões e ensino. São Paulo: Parábola Editorial, 2011. pp. 137-152. 


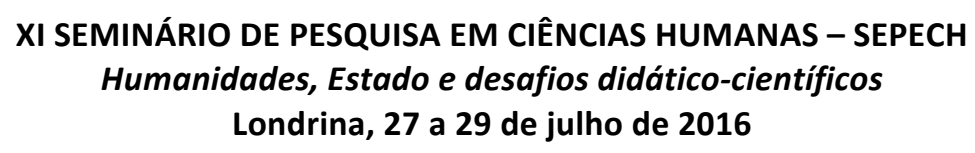

; VASCONCELOS, L. J. de. Multimodalidade, gênero textual e leitura. In: BUNZEN, Clecio; MENDONÇA, Márcia. Múltiplas linguagens para o Ensino Médio. São Paulo: Parábola Editorial, 2013.

DOLZ, J.; NOVERRAZ, M.; SCHNEUWLY, B. Seqüências didáticas para o oral e a escrita: apresentação de um procedimento. In: DOLZ, J.; SCHNEUWLY, B. Gêneros orais e escritos na escola. [Tradução e organização: Roxane Rojo e Glaís Sales Cordeiro]. Campinas, SP: Mercado de Letras, 2004.

GOODY, J. (Org.) Literacy in tradicional societies. Cambridge: Cambridge University Press, 1969.

KATO, M. O aprendizado da leitura. 4 ed. São Paulo: Martins Fontes, 1995.

KOCH, I. V. . Ler e compreender os sentidos do texto. São Paulo: Contexto, 2011.

MARCUSCHI, L. A. O Hipertexto como um novo espaço de escrita em sala de aula.Linguagem \& Ensino (UCPel), Pelotas - RS, v. 4, n. 1, p. 79-112, 2001.

. Gêneros textuais emergentes no contexto da tecnologia digital. In.:

XAVIER. Antônio Carlos (Org.). Hipertexto e gêneros digitais: novas formas de construção de sentido. 2 ed. Rio de Janeiro: Lucerna, 2005.

OLIVEIRA, D. M. Gêneros multimodais e multiletramentos: novas práticas de leitura na sala de aula. In: VI Fórum Identidades e alteridades II Congresso Nacional Educação e Diversidade - 2013 UFS - Itabaiana/SE, Brasil. Anais.

OLSON, D. From Utterance to text: the bials of language in speech and writing. Harvard Education Review, vol.47 p.254-279, 1977.

ONG, W. Literacy and orality: the technologizing of the word. Nova York: Methuen, 1982.

PAIVA, F. A. O gênero textual infográfico: leitura de um gênero textual multimodal por alunos da $1^{\mathrm{a}}$ série do ensino médio. Revista L@el em (Dis-)curso. Volume 3, 2011, p. $87-101$.

A Leitura de Infográficos da Revista Superinteressante: procedimentos de leitura e compreensão. Programa de Pòs-graduação em Estudos Linguisticos. Universidade Federal de Minas Gerais: Belo Horizonte, 2009

PINHEIRO, P. A.. Gêneros (digitais) em foco: por uma discussão sócio-histórica. Alfa: Revista de Linguística 54.1 (2010): 33+. Academic OneFile. Web. 10 set. 2015

ROJO, R.; MOURA, E. Multiletramentos na escola. São Paulo: Parábola Editorial, 2012. 


\section{SEMINÁRIO DE PESQUISA EM CIÊNCIAS HUMANAS - SEPECH \\ Humanidades, Estado e desafios didático-científicos}

Londrina, 27 a 29 de julho de 2016

SHEPHERD, M.; WATTERS, C. The Functionality Attribute of Cybergenres. Proceedings of the 32nd Hawaii International Conference on System Sciences 1999.

SOLÉ, I. Estratégias de Leitura. 6 ed. Porto Alegre: Artmed, 1998.

STREET, B. V. Letramentos sociais: abordagens críticas do letramento no desenvolvimento, na etnografia e na educação. São Paulo: Paráabola Editorial, 2014. 